\title{
INFRASTRUCTURE AND INEQUALITY: INSIGHTS FROM INCORPORATING KEY ECONOMIC FACTS ABOUT HOUSEHOLD HETEROGENEITY
}

\author{
DAVID KLeNerT \\ Mercator Research Institute on Global Commons and Climate Change, \\ Technical University of Berlin, \\ and \\ Potsdam Institute for Climate Impact Research
}

Linus Mattauch

Mercator Research Institute on Global Commons and Climate Change Ottmar Edenhofer Mercator Research Institute on Global Commons and Climate Change, Potsdam Institute for Climate Impact Research, and

Technical University of Berlin

\section{KAI LESSMANN}

Potsdam Institute for Climate Impact Research and

Mercator Research Institute on Global Commons and Climate Change

\begin{abstract}
We study the impacts of investment in public capital on equity and efficiency. Taking into account stylized facts on wealth accumulation, we model agent heterogeneity through differences in saving behavior, income source and time preference. We find that in the long run, public investment is Pareto-improving and that it reduces inequality in wealth, welfare, and income at the same time, if it is financed by a capital tax. Consumption tax financing is also Pareto-improving but distribution-neutral. Only for labor tax financing, a trade-off between equity and efficiency occurs. Additionally, we find that agents differ in their preferred tax rates. The results for capital and labor tax financing are valid for both, the case of decreasing and constant returns to accumulable factors.
\end{abstract}

Keywords: Distribution, Heterogeneous Saving, Infrastructure, Public Capital 


\section{INTRODUCTION}

Public investment in infrastructure has recently received much attention as an attractive option for accomplishing two main objectives of economic policy: Promoting efficiency and growth as well as reducing inequality in wealth. Evidence from the empirical literature suggests that investment in infrastructure can have a decreasing effect on inequality [Calderón and Servén (2014a)], while enhancing growth at the same time [Calderón and Servén (2014b)]. These authors assert that for both relationships, little is known about the magnitude of the effects and the underlying mechanisms.

In this article, we confirm that public investment can enhance equality, but show that, in the long run, this depends strongly on the financing mechanism: Capital tax financing can both promote inequality reduction in wealth, welfare, and income and enhance the total level of these variables, when its revenue is spent on public investment. Financing public capital with a consumption tax enhances the efficiency but leaves the level of inequality virtually unchanged. The result on consumption tax financing is, to our knowledge, novel in the literature, as is the result that inequality in wealth and welfare is reduced if public investment is financed by a capital tax. In our analysis, the frequently discussed trade-off between equity and efficiency only occurs for the case of labor tax-financed public investment, which indeed increases inequality in all indicators.

Additionally, the optimal tax level for each household is determined and it is shown that agents differ in their preferred tax rates. This is an extension of the result by Barro (1990) that there is a trade-off between providing productive public investment and its distortionary financing, to the case of heterogeneous households. Nevertheless, up to a certain rate of all taxes, total levels of wealth, welfare, and income are always enhanced, making all agents better off, and thus constituting a Pareto improvement. Our results rest on an approach of modeling household heterogeneity that is based on stylized facts about income sources, saving behavior, and time preferences.

Previous theoretical work comes to ambiguous conclusions on the distributional effects of infrastructure investment: Alesina and Rodrik (1994) show that inequality-reducing public investment always decreases the efficiency. In Glomm and Ravikumar (1994), it is found that in the long run, the impact of public investment in a productivity-enhancing knowledge stock is neutral on the distribution. The authors consequently argue that there is no equity-efficiency trade-off in the long run when it comes to public investment. Chatterjee and Turnovsky (2012) find that labor and consumption tax financing increase income inequality in the long run, while capital tax financing can decrease income inequality. Regarding the distribution of wealth and welfare, they show that public investment always enhances inequality in the long run, independent of the financing mechanism.

We attribute these results to the way heterogeneity is introduced: In the aforementioned studies, agents differ only in their initial capital endowments. Only Alesina and Rodrik (1994) additionally account for differences in income sources. 
A model with these types of heterogeneity assumptions; however, is not able to reproduce the observed wealth distribution [Cagetti and De Nardi (2008); De Nardi and Yang (2014)]. "[F]or many purposes, the representative-consumer model should be abandoned in favor of a model that matches key microeconomic facts" [Carroll (2000a, p. 110)]. Here, we comply with this request: By departing from the standard assumptions on heterogeneity our results on consumption tax financing of infrastructure differ from previous studies, as well as the results on capital tax financing, when inequality in wealth and welfare is considered.

In our model, we account for the following economic facts: ${ }^{1}$ Rich households have been shown to save in a dynastic fashion, while households in the middleincome cohorts exhibit more of a life-cycle saving behavior [Attanasio (1994); Browning and Lusardi (1996); Dynan et al. (2004)]. Neither motive in isolation can reproduce the observed wealth distribution [Carroll (2000b)]. The wealthier a household is, the more his income sources shift away from wage income toward business and capital income and the more likely it is that he is self-employed [Quadrini (1997); Wolff (1998); Diaz-Gimenez et al. (2011)]. Lawrance (1991) and Green et al. (1996) demonstrate that wealthier households have lower rates of time preference. Krusell and Smith (1998) show that allowing for different time preference rates is a key factor in reproducing the observed wealth distribution.

We develop a general equilibrium model in which high-income households are characterized by having a dynastic saving behavior and capital income as their only income source. Middle-income households are life-cycle savers, which split their labor income between current consumption and savings for retirement. Lowincome households do not save or even dissave and are thus omitted. ${ }^{2}$ Our model is related to the model developed in Michl (2009) and can also be seen as an extension of the models described in Stiglitz $(1969,2015)$ that incorporates optimizing agents. High-income households are modeled as a representative infinitely lived agent (ILA), and the middle-income households are modeled as a representative overlapping-generations agent. ${ }^{3}$ The model also allows for agents to differ in their time preference rate. We then calibrate the model to closely match stylized facts of the U.S. economy. In Mattauch et al. (2016), we show analytically, for a basic version of the model, that under these heterogeneity assumptions, capital taxfinanced public investment can enhance productivity while reducing inequality. Here, we generalize the basic model, in order to assess more channels through which public investment affects the distribution of wealth, welfare, and income. We include consumption and labor taxation as revenue-raising mechanisms, introduce a labor-leisure choice and model public capital as affecting both production, and utility. ${ }^{4}$ Due to our choice of two optimizing agents with distinct saving behavior, our model does not nest the other approaches mentioned before, but instead complements them by accounting for stylized facts on heterogeneous saving behavior.

Our article makes two main contributions. First, we demonstrate that introducing heterogeneity based on empirically observed household behavior has far-reaching consequences: Depending on its financing mechanism (capital, consumption, or labor taxation), public investment can either have a decreasing, neutral, or increasing 
impact on inequality. Our second contribution is that our modeling approach yields meaningful results for both endogenous growth and steady-state convergence and our results do not depend on the assumption of homogeneous time preference rates across all agents.

Our concept of heterogeneity, the first contribution, allows us to draw the following conclusions: (i) Higher levels of wealth, welfare, and income and a reduced dispersion of these economic variables across households in the long run can be achieved by a policy of capital tax-financed public investment. Regarding income inequality, this result confirms the study by Chatterjee and Turnovsky (2012). It differs from their findings when inequality in wealth or welfare is considered and from the results derived in Alesina and Rodrik (1994) and Glomm and Ravikumar (1994). (ii) Financing public capital through a consumption tax has virtually no effect on the distribution of these variables in the long run. ${ }^{5}$ (iii) By determining the tax level that maximizes each household's steady-state utility, we find that households differ in their preferred tax level. As a consequence of this result, there is no single optimal tax rate when financing public investment.

Our second contribution is that our results are very robust with regard to the modeling strategy (see Section 4.2): The results for labor and capital tax financing remain qualitatively the same for endogenous growth as well as for steady-state convergence of the model. ${ }^{6}$ All results hold for a wide range of heterogeneous time preference rates across households and the model behavior does not change for homogeneous time preference rates. Furthermore, the results remain qualitatively the same if only public capital [as in Barro (1990)], or only private capital [as in Romer (1986)], is productivity-enhancing.

The remainder of this article is organized as follows: Section 2 outlines the model and its calibration. In Section 3, we characterize the model results for convergence to the steady state. In Section 4.1, we present extensions to the model such as additional financing mechanisms (lump-sum taxes and government debt) for public investment and the endogenous growth version of the model. In Section 4.2, we analyze the model's robustness to variations in the model assumptions and in parameter values. Section 5 concludes the article.

\section{MODEL}

The three most important features of the model are that (i) household heterogeneity is modeled through differences in saving behavior and differences in income sources. High-income households whose bequest motive is perfectly altruistic and who rely only on capital income are modeled as a representative ILA. Middleincome households who save according to a life-cycle motive are modeled as a representative overlapping-generations agent with labor and capital income. The households can also differ in their time preference rate. (ii) Public and private capital are combined in a weighted product, the composite externality. By varying the weight parameter we can vary the role capital plays in production: When the weight parameter of private capital equals one the role of private capital is analogous to 
the case examined by Romer (1986). For a weight parameter of private capital equal to zero, public capital plays the same role as in the model by Barro (1990). (iii) Public capital plays a dual role in our model, enhancing both the value of leisure in the utility function, and total productivity. Since it would not provide us with additional insights, we neglect population growth and assume that the size of the representative households does not change. Still, we account for the fact that the households are different in size in the calibration of the model (see Section 2.7).

\subsection{The Firm}

The production sector is modeled as a single representative firm. Labor is provided by the middle-income household only, while both households supply capital. Production occurs with a Cobb-Douglas production function:

$$
F\left(K_{t}, h_{t}\right)=\hat{A} K_{t}^{\alpha} h_{t}^{1-\alpha}, \quad \hat{A}=A X_{p, t}^{\beta}, \quad 0<\alpha, \beta<1,
$$

with $h_{t}=1-l_{t}$ being the portion of the total time endowment that middle-income households dedicate to work. The remainder of their time is used for leisure $l_{t}$.

$X_{p, t}=K_{t}^{\epsilon} K_{G, t}^{1-\epsilon}$, with $0<\epsilon<1$, represents a composite production externality, modeled as a weighted product of private and public capital. The capital entering the production function is the sum of the middle-income households' savings from the last period $S_{t-1}$ and the high-income households' capital $K_{h, t}$ :

$$
K_{t}=S_{t-1}+K_{h, t} .
$$

Note that for $\alpha+\beta<1$ the economy converges to a steady state. But if $\alpha+\beta=1$ and if the ratio of public to private capital remains constant, the model will display endogenous growth behavior. This can be deduced by an equivalent of equation (1):

$$
F\left(K_{t}, h_{t}\right)=A K_{t}^{\alpha+\beta}\left(h_{t}\right)^{1-\alpha}\left(\frac{K_{G, t}}{K_{t}}\right)^{(1-\epsilon) \beta} .
$$

A representative firm maximizes its profit:

$$
\Pi_{t}=F\left(K_{t}, h_{t}\right)-\left(r_{t}+\delta_{K}\right) K_{t}-w_{t} h_{t},
$$

where $r_{t}$ and $w_{t}$ represent the rental rates the firms have to pay to the households for capital and labor and $\delta_{k}$ is the depreciation rate of private capital. The following first-order conditions are obtained:

$$
\begin{gathered}
r_{t}+\delta_{K}=\frac{\partial F\left(K_{t}, h_{t}\right)}{\partial K_{t}}=\alpha A\left(\frac{h_{t}}{K_{t}}\right)^{1-\alpha} X_{p, t}^{\beta}, \\
w_{t}=\frac{\partial F\left(K_{t}, h_{t}\right)}{\partial h_{t}}=(1-\alpha) A\left(\frac{K_{t}}{h_{t}}\right)^{\alpha} X_{p, t}^{\beta} .
\end{gathered}
$$




\subsection{The High-Income Households}

The high-income households are modeled as a representative ILA. They derive utility from either consumption $C_{t}$ or leisure $l_{h}$, which is fixed for the ILA. We later show in Section 4.2.2 that the results of this paper are independent from the level of leisure the high-income households receive as long as it remains in a plausible range. Future utility is discounted by the time preference rate $\rho_{h}$. Lifetime utility is given by

$$
U=\sum_{t=0}^{t_{\text {final }}} u_{t}^{\mathrm{ILA}} \cdot \frac{1}{\left(1+\rho_{h}\right)^{t}},
$$

with

$$
u_{t}^{\mathrm{ILA}}=\left(\frac{1}{b}\right)\left(C_{t}^{a}+\theta\left(X_{u, t} l_{h}\right)^{a}\right)^{(b / a)},
$$

where $a=1-\frac{1}{\sigma_{\text {Intra }}}$, with $\sigma_{\text {Intra }}$ being the intratemporal elasticity of substitution between consumption and leisure and $b=1-\frac{1}{\sigma_{\text {Inter }}}$, with $\sigma_{\text {Inter }}$ being the intertemporal elasticity of substitution. $\theta$ is a weight factor for the leisure term and $X_{u, t}=K_{t}^{\varphi} K_{G, t}^{1-\varphi}$, with $0<\varphi<1$, is the composite externality as in the production sector, but with a different exponent $\varphi$.

The ILA chooses her levels of consumption $C_{t}$ and capital accumulation $K_{h, t}$ to maximize equation (5) according to her budget constraint:

$$
K_{h, t+1}-K_{h, t}=\left(1-\tau_{K}\right) r_{t} K_{h, t}-\left(1+\tau_{c}\right) C_{t},
$$

where $\tau_{c}$ represents a consumption and $\tau_{k}$ a capital income tax. The agent takes the returns to capital, $r_{t}$, as well as all taxes as given by the firm and the government, respectively. Solving the optimization problem yields the following intertemporal decision equation (details on the derivation can be found in Appendix B):

$$
\frac{\left(\frac{\partial u_{t-1}^{\mathrm{ILA}}}{\partial C_{t-1}}\right)}{\left(\frac{\partial u_{t}^{\mathrm{ILA}}}{\partial C_{t}}\right)}=\frac{1+\left(1-\tau_{K}\right) r_{t}}{1+\rho_{h}}
$$

\subsection{The Middle-Income Households}

The middle-income households are modeled as a representative Diamond-type overlapping-generations agent, to whom we will also refer as an "OLG" agent and who lives for just two periods. The duration of each period is 30 years. In the first period, the agent decides how to divide her fixed time endowment (which is normalized to 1$)$ between work $\left(h_{t}=1-l_{y, t}\right)$ and leisure $\left(l_{y, t}\right)$ and how much of her labor income $\left(w_{t}\right)$ she saves for the second period [equation (9)]. In the second period, the savings plus the interests are consumed [see equation (10)]. We use the 
subscript "y" to denote the young (first-period) agent, and "o" to denote the old (second-period) agent.

The lifetime utility of the OLG agent is given by

$$
u_{t}^{\mathrm{OLG}}=\frac{1}{b}\left(C_{y, t}^{a}+\theta\left(X_{u, t} l_{y, t}\right)^{a}\right)^{b / a}+\frac{1}{\left(1+\rho_{m}\right)} \frac{1}{b}\left(C_{o, t+1}^{a}+\theta\left(X_{u, t+1} l_{o}\right)^{a}\right)^{b / a} \text {, }
$$

where $l_{o}$ is the fixed leisure endowment of the old agent. We show in Section 4.2.2 that the level of this parameter does not change the character of the results as long as it remains in a plausible range. The young agent discounts her own old age by a factor $\rho_{m}$. The agent chooses $l_{y, t}$ and $S_{t}$ to maximize her lifetime utility subject to the two budget constraints:

$$
\begin{aligned}
& \left(1+\tau_{c}\right) C_{y, t}=\left(1-\tau_{w}\right) w_{t}\left(1-l_{t}\right)-S_{t}, \\
& \left(1+\tau_{c}\right) C_{o, t+1}=\left(1+\left(1-\tau_{K}\right) r_{t+1}\right) S_{t},
\end{aligned}
$$

where $\tau_{w}$ is a tax on labor. Solving the optimization problem yields the equations of the inter- and intra-temporal decision problem (details on the derivation can be found in Appendix C)

$$
\begin{gathered}
\frac{\left(\frac{\partial u_{t}^{\mathrm{OLG}}}{\partial C_{y, t}}\right)}{\left(\frac{\partial u_{t}^{\mathrm{OLG}}}{\partial C_{o, t+1}}\right)}=\left(1+\left(1-\tau_{K}\right) r_{t+1}\right), \\
\frac{\left(\frac{\partial u_{t}^{\mathrm{OLG}}}{\partial C_{y, t}}\right)}{\left(\frac{\partial u_{t}^{\mathrm{OLG}}}{\partial l_{y, t}}\right)}=\frac{\left(1+\tau_{c}\right)}{\left(1-\tau_{w}\right) \cdot w_{t}}
\end{gathered}
$$

\subsection{The Government}

The government levies taxes to finance investment in a public capital stock $K_{G}$. Public capital depreciates at the rate $\delta_{G}$. The tax level is set exogenously, which means that the government does not optimize. We nevertheless can find the preferred tax rates of each agent by comparing their utilities in different steady states. The government's budget equation is thus

$$
K_{G, t+1}-K_{G, t}=\tau_{K} \cdot r_{t} \cdot K_{t}+\tau_{w} \cdot h_{t} \cdot w_{t}+\tau_{c} \cdot\left(C_{t}+C_{y, t}+C_{o, t}\right)-\delta_{G} K_{G, t} .
$$

Subsequently, the relative merit of financing public investment by the three distinct taxes will be compared. 


\subsection{Equilibrium and the Pasinetti Paradox}

For $\alpha+\beta<1$, the system converges to a steady state for all parameter combinations evaluated numerically (see Table 1 for the standard calibration and Table 7 at the end of the article for the parameter ranges evaluated in the sensitivity analysis). In the following, variables at their steady-state levels are denoted by a tilde. We see from equation (7) that in the steady state, the high-income households' rate of pure time preference determines the interest rate of the aggregate economy $\tilde{r}$ :

$$
\frac{1+\left(1-\tau_{K}\right) \tilde{r}}{1+\rho_{h}}=1 \Rightarrow \tilde{r}=\frac{\rho_{h}}{\left(1-\tau_{K}\right)} .
$$

This entails that in our model a form of the Pasinetti (1962) Paradox occurs. In its original formulation the paradox states that in a Solow model with two types of households, one of them only receiving income through capital interests-the "capitalists"- the steady-state interest rate is solely determined by the "capitalists" savings rate. Similarly, in our framework the long-run interest rate is only determined by the high-income households' time preference rate (and the capital tax rate), independent of the high-income households' income sources. The paradox furthermore implies that when middle-income households increase their saving, the high-income households' saving will be relatively lower. For more details on the Pasinetti Paradox in the context of a simpler version of this model see Mattauch et al. (2016). Note that the Pasinetti Paradox does not occur for endogenous growth, since in that case the interest rate no longer depends only on the time preference rate of the high-income household. The remaining equations that characterize the steady state can be found in Appendix D.

\subsection{Measure of Distribution}

We take the coefficient of variation $\sigma_{j}$ with $j \in[\mathrm{K}, \mathrm{U}, \mathrm{Inc}]$ as a measure of dispersion in wealth, welfare, and income [see, e.g., Ray (1997) for details on inequality measures]. The cohorts represented by the two agents are of unequal size (see Section 2.7 on calibration), which has to be reflected in the calculation of the coefficient. In the following, $\mathrm{N}$ is the total size of both cohorts, while $N_{\mathrm{m}}$ and $N_{\mathrm{h}}$ stand for the size of the middle and the high-income cohort. The index " $p c$ " marks a per capita variable:

$$
\sigma_{K}=\frac{\sqrt{\frac{1}{N}\left(N_{\mathrm{m}}\left(S_{\mathrm{pc}}-\mu_{K}\right)^{2}+N_{\mathrm{h}}\left(K_{h, \mathrm{pc}}-\mu_{K}\right)^{2}\right)}}{\mu_{K}},
$$

with $\mu_{K}$ being the mean:

$$
\mu_{K}=\frac{N_{\mathrm{h}} K_{h, \mathrm{pc}}+N_{\mathrm{m}} S_{\mathrm{pc}}}{N} .
$$


TABLE 1. Standard calibration of the model

\begin{tabular}{lllc}
\hline Symbol & \multicolumn{1}{c}{ Parameter } & Value & Value (p.a.) \\
\hline$\alpha$ & Elasticity of capital in production & 0.4 & - \\
$\beta$ & Exponent of public capital in production & 0.2 & - \\
$\delta_{G}$ & Depreciation of public capital & 0.7 & $4 \%$ \\
$\delta_{k}$ & Depreciation of private capital & 0.7 & $4 \%$ \\
$\epsilon$ & Private capital share in $X_{p, t}$ & 0.6 & - \\
$\varphi$ & Private capital share in $X_{u, t}$ & 0.6 & - \\
$l_{h}, l_{o}$ & Leisure of agents with only capital income & 0.71 & - \\
$\rho_{h}$ & High inc. households' time preference rate & 0.45 & $1.2 \%$ \\
$\rho_{m}$ & Middle inc. households' time preference rate & 6 & $6.7 \%$ \\
$\sigma_{\text {Inter }}$ & Intertemporal elasticity of substitution & 0.4 & - \\
$\sigma_{\text {Intra }}$ & Intratemporal elasticity of substitution & 0.76 & - \\
$\theta$ & Share of leisure in utility function & 1.75 & - \\
\hline
\end{tabular}

\subsection{Calibration}

We calibrate the model such that in the baseline scenario the high-income households make up five percent of the population, while owning $62 \%$ of total wealth and the middle-income households make up the next $55 \%$ of the population while owning the remaining $38 \%$ of total wealth. These numbers are chosen to match a study on the wealth distribution in the United States [Wolff (2010)]. The model also roughly complies with the fact that $50-60 \%$ of U.S. net worth accumulation is due to wealth transfers from one generation to another [Gale and Scholz (1994)]. In the baseline scenario, a minimal stock of public capital is already provided through a consumption tax, which is the least distortionary of the three types of taxes.

The above results use the parameterization displayed in Table 1. All values are chosen for timesteps of 30 years.

We use the study by Chatterjee and Turnovsky (2012) as a benchmark for our calibration. Whenever, we deviate from their calibration the reason lies in the different type of household heterogeneity used in our model: We model the households such that high-income households have a lower time preference rate than middle-income households, in accordance with Lawrance (1991), Dynan et al. (2004), and Green et al. (1996). Leisure is constant for agents receiving only capital income, which is true for the old middle-income household and the high-income household. These assumptions are analyzed for their robustness in Section 4.2.2. The parameter ranges in which our results remain qualitatively the same is given in Table 7 at the end of the paper.

\section{RESULTS}

In this section, we present the results for the case of decreasing returns to accumulable factors and thus of convergence to the steady state. We assess the impact of our assumption of household heterogeneity on the performance of three 
revenue-raising mechanisms for public investment: capital income taxation, labor income taxation, and consumption taxation. We analyze the impact of these policies on wealth, welfare, income, the distribution of these variables between different households, and on aggregate output. The various policies are evaluated relative to a scenario in which a basic level of public capital is supplied by a $2 \%$ consumption tax.

In the long run, investment in public capital can be inequality-decreasing, distribution-neutral or inequality-increasing, depending on the financing mechanism: Capital taxation as a financing option reduces inequality, while a labor tax increases inequality and consumption taxation has a neutral effect on the distribution. ${ }^{7}$ All three financing mechanisms promote efficiency up to a certain tax level.

Furthermore, by comparing the steady-state utility levels for varied tax values, we determine the tax level that maximizes each household's welfare for each financing mechanism.

The short-run distributional effects can, for some financing mechanisms, be contrary to the long-run effects: for instance, a labor tax can decrease short-run wealth inequality even though it is inequality-increasing in the long run. A consumption tax is almost distribution-neutral in the long run, but has strong distributional impacts in the short run.

This section is structured as follows: In the first part, Section 3.1, we describe the effect of each financing mechanism for public capital for the case of convergence to the steady state. We discuss the effects of the policy on welfare, capital and income of each agent, as well as on aggregate output and on the dispersion of wealth, welfare, and income. Furthermore, each household's welfare-maximizing tax level is determined for each financing mechanism. In Section 3.1.4, the different financing mechanisms are compared in terms of their efficiency and equity implications. Finally, in Section 3.2, we describe the effects of the policies on the transitional dynamics.

\subsection{Long-Run Results}

In this section, we investigate the long-run effects of increased public investment for a broad range of exogenously given capital, labor, and consumption tax rates. We write $d X$ to denote the percentage change of the variable $X$ with respect to the baseline scenario of a $2 \%$ consumption tax.

To avoid a discussion on how to compare aggregate utilities of short-lived OLG agents to that of ILAs, in this section we consider only steady-state utility levels, to which we will refer as welfare. We denote the tax levels that maximize output and each agent's welfare level as $\tau_{Y}^{\max }, \tau_{u, \text { ILA }}^{\max }$, and $\tau_{u, \mathrm{OLG}}^{\max }$.

3.1.1. Capital Tax. When financing an increase in public capital with a tax on capital income, we find the following four effects:

1. Dispersion in wealth, welfare and income decreases for rising $\tau_{k}$ (see Figure 1, left).

2. Output is maximized for a $30 \%$ capital tax. 

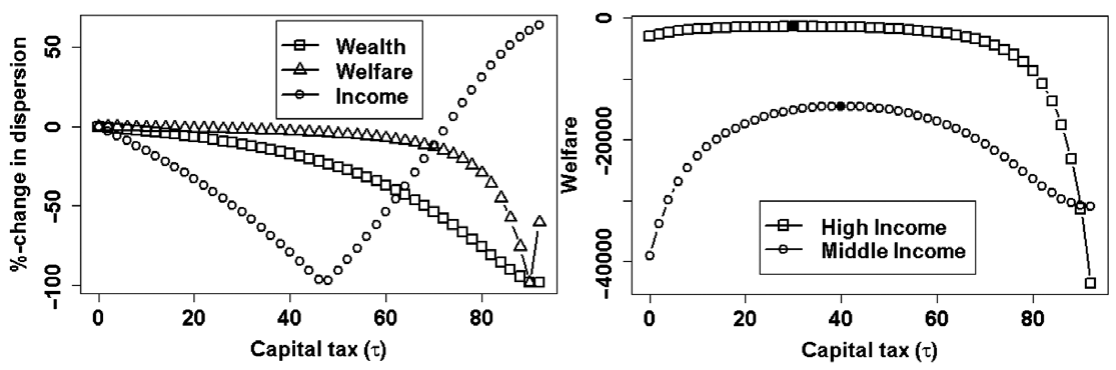

FIGURE 1. Effects of capital tax-financed public investment on the dispersion of wealth, welfare and income (left) and on the welfare of both agents (right). The downward spikes in the left panel reflect the points where middle-income households are equal in a certain variable to high-income households. For even higher tax rates the dispersion increases again, but this time the middle-income households are comparatively better off.

3. For tax rates up to $64 \%$ the policy is Pareto-improving (see Figure 1, right).

4. Middle-income households prefer a higher capital tax rate $(40 \%)$ than high-income households (30\%) (see Figure 1, right).

These results are explained as follows: Since the model has the Pasinetti property (see also Section 2.5), a capital tax increases the interest rate in the long run [see equation (14)], high-income households reduce their savings and thus the income and wealth dispersion decreases. For low capital taxes the public capital stock and with it the composite externality increases, which increases the returns to labor [see equation (4)] and thus further decreases the dispersion in income. ${ }^{8}$ These effects combined lead to a larger reduction in consumption and thus in welfare for high-income households than for middle-income households. Thus, dispersion in all three variables decreases. ${ }^{9}$

A Pareto improvement exists because of the positive effect of the composite externality on utility and production. Whenever the positive effect of public investment outweighs the negative effect of taxation Pareto improvements are possible.

3.1.2. Labor Tax. A labor tax affects only the middle-income households, since the high-income households do not receive any labor income. The effects of labor tax-financed public capital are displayed in Figure 2. Our main findings are as follows:

1. Dispersion in all three variables increases (see Figure 2, left).

2. Output is maximized for a labor tax bigger than $92 \%$.

3. The policy is Pareto-improving up to more than $92 \%$ (see Figure 2, right).

4. Middle-income households prefer a lower income tax rate $(68 \%)$ than high-income households (>92\%) (see Figure 2, right).

The intuition behind these results is as follows: A labor tax solely affects the middle-income households' income, which increases the income dispersion strongly. Since the middle-income households' saving decision depends on the 

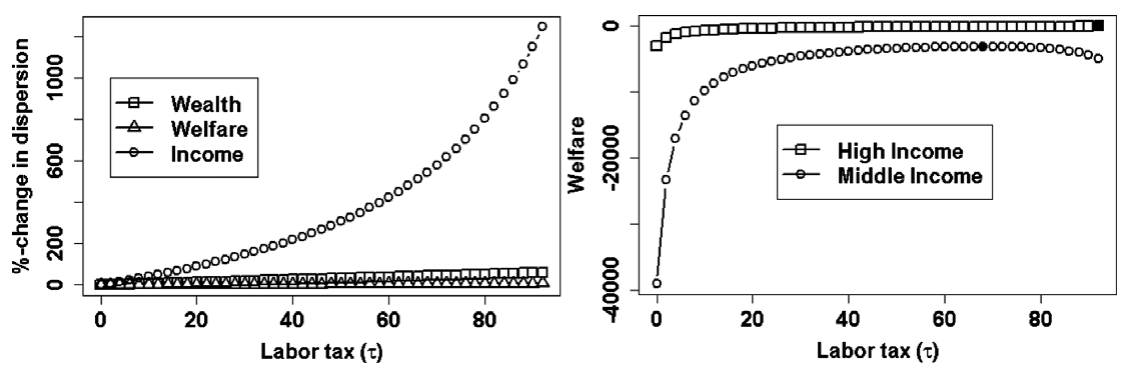

FIGURE 2. Effects of labor tax-financed public capital on the dispersion of wealth, welfare, and income (left) and on the welfare of both agents (right). The high-income households prefer the maximum wage tax rate, since they do not receive wage income but benefit from public investment. The tax rate preferred by the middle-income households is quite high, which is a consequence of the current calibration, where the benefits of public investment outweigh the negative effects of a labor tax up to a tax rate of $68 \%$.

level of the wage income, their savings decrease, which causes the wealth dispersion to increase. Labor taxation increases the leisure consumption ratio, which can be seen in equation (C.5). The increasing composite externality has an opposing effect on the leisure consumption ratio (since $a<0$, for $\sigma_{\text {Intra }}<1$ ), which dominates with the current parameterization (specified in Section 2.7), so leisure decreases. The high-income household experiences a stronger increase in welfare due to its non-taxed income and the leisure-enhancing effect of the composite externality, while the middle-income household has reduced consumption through labor income taxation and reduced leisure, which causes inequality in welfare also to increase. The mechanism for the Pareto improvement described for the capital tax also applies here, it is even stronger since labor taxation decreases the private capital stock less than capital taxation.

3.1.3. Consumption Tax. The consumption tax has the broadest tax base of the three taxes since the burden falls on all households: the ILA, as well as the young and the old overlapping-generations agents are taxed. Financing public capital with a consumption tax has the following effects:

1. Output is maximized for a tax rate of $>90 \%$.

2. The policy is Pareto-improving for consumption taxes up to more than $90 \%$ (see Figure 3, right).

3. Both households prefer a consumption tax $>90 \%$ (see Figure 3, right).

4. Dispersion in all three variables changes only slightly (see Figure 3, left).

Consumption tax-financed public capital acts on the distribution in three ways: (i) The burden of the consumption tax itself falls on all agents (young/old OLG agent and ILA). However, the young OLG agent can react to the tax by adjusting its labor supply. For the other agents, leisure is assumed to be constant. A reduction in leisure reduces the leisure component in the utility function but 

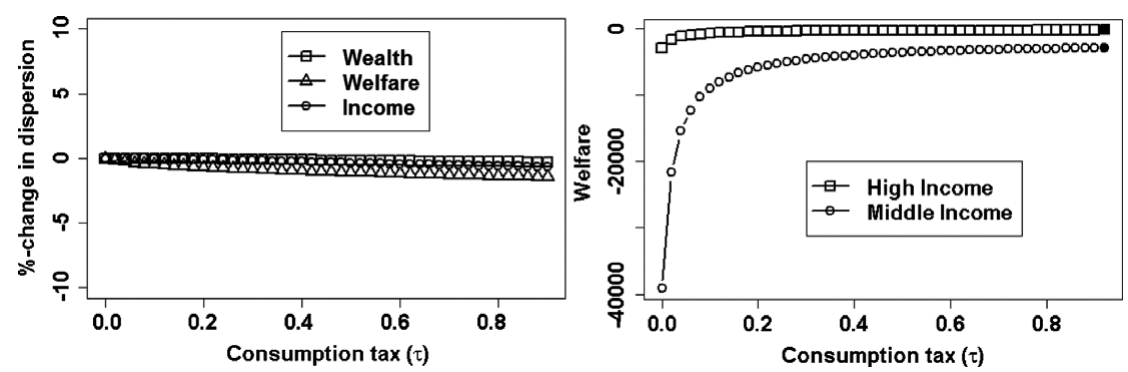

FIGURE 3. Effects of consumption tax-financed public capital on the dispersion of wealth, welfare and income (left) and on the welfare of both agents (right).

potentially increases income due to more hours worked. (ii) Public capital entering the production affects all agents via increased factor prices (in the short run). In order to maintain the interest rate at its Pasinetti level, the high-income household has to decrease its savings rate relative to that of the middle-income household. The long-run wage rate remains at increased levels in the steady state, which leads to an increased steady-state income and increased saving for the middle-income household. (iii) Public capital entering the utility function increases both agents' utility obtained through leisure. Only the young OLG agent has an endogenous labor-leisure choice and can react to increased public spending. For the standard calibration, an increase in public capital leads to a decrease in leisure [see also equation (C.5)], which leads to an increased income.

In sum, these effects lead to the following outcome: The leisure-reducing effect of public capital (i) outweighs the direct effect of the consumption tax (ii) by far, so the leisure of the young OLG agent decreases. For the standard calibration and the parameter variations given in Table 7 at the end of this article, the increase in the high and the middle-income households' income is almost of the same size, so the resulting difference in the income, wealth, and welfare distribution are very small and this policy appears almost distribution-neutral. ${ }^{10}$

Consumption tax financing always increases efficiency up to very high tax rates, since the Pasinetti property of the model ensures high capital accumulation, which has a positive effect on wages. Both agents steady-state income is then increased. Even though the agents' consumption decreases at some point, the utility-enhancing effect of public capital more than compensates for this loss. For that reason, all agents prefer consumption tax levels up to $90 \%$.

\subsubsection{Summary: Comparing the Different Taxes. In our model, tax-financed} public capital acts on the distribution in three different ways: First, through a change in the policy, the aggregate level of capital changes. Second, agents are affected differently by different tax instruments and finally, agents react to policies by changing their leisure level and their saving behavior. Since all taxes differ in their impact on aggregate capital, in their differential impact on the households and on the labor-leisure choice, each tax has different effects on equity and efficiency. 
TABLE 2. Steady-state effects of a capital tax-financed increase in public spending

\begin{tabular}{lcccccc}
\hline & $\mathrm{dY}(\%)$ & $d u_{\mathrm{ILA}}(\%)$ & $d u_{\mathrm{OLG}}(\%)$ & $d \sigma_{K}(\%)$ & $d \sigma_{u}(\%)$ & $d \sigma_{\mathrm{Inc}}(\%)$ \\
\hline$\tau_{Y}^{\max }=0.3$ & 31.5 & 53.6 & 61.5 & -10.8 & -1.8 & -54.2 \\
$\tau_{u, \mathrm{ILA}}^{\max }=0.3$ & 31.5 & 53.6 & 61.5 & -10.8 & -1.8 & -54.2 \\
$\tau_{u, \mathrm{OLG}}^{\max }=0.4$ & 29.1 & 51.3 & 63.2 & -16.9 & -2.9 & -79.1 \\
\hline
\end{tabular}

In the column on the left, the levels of capital tax rates that maximize output and utility of the different agents are given. In the remaining columns the changes in output, welfare, and dispersion are given, as compared to the baseline.

TABLE 3. Steady-state effects of a labor tax-financed increase in public spending

\begin{tabular}{lcccccc}
\hline & $\mathrm{dY}(\%)$ & $d u_{\mathrm{ILA}}(\%)$ & $d u_{\mathrm{OLG}}(\%)$ & $d \sigma_{K}(\%)$ & $d \sigma_{u}(\%)$ & $d \sigma_{\mathrm{Inc}}(\%)$ \\
\hline$\tau_{Y}^{\max }>0.92$ & 443.2 & 98.4 & 87.8 & 59.4 & 7.9 & 1245 \\
$\tau_{u, \mathrm{ILA}}^{\max }>0.92$ & 443.2 & 98.4 & 87.8 & 59.4 & 7.9 & 1245 \\
$\tau_{u, \mathrm{OLG}}^{\max }=0.68$ & 276.9 & 96.7 & 92.2 & 43.9 & 5.3 & 539.6 \\
\hline
\end{tabular}

In the column on the left, the levels of labor tax rates that maximize output and utility of the different agents are given. In the remaining columns the changes in output, welfare, and dispersion are given, as compared to the baseline. Some values are outside the feasible range of taxes in our model and are thus marked with a ">" sign.

TABLE 4. Steady-state effects of a consumption tax-financed increase in public spending

\begin{tabular}{lcccccc}
\hline & $\mathrm{dY}(\%)$ & $d u_{\mathrm{ILA}}(\%)$ & $d u_{\mathrm{OLG}}(\%)$ & $d \sigma_{K}(\%)$ & $d \sigma_{u}(\%)$ & $d \sigma_{\mathrm{Inc}}(\%)$ \\
\hline$\tau_{Y}^{\max }>0.9$ & 221.3 & 91.4 & 92.6 & -0.3 & -1.4 & -0.7 \\
$\tau_{u, \mathrm{ILA}}^{\max }>0.9$ & 221.3 & 91.4 & 92.6 & -0.3 & -1.4 & -0.7 \\
$\tau_{u, \mathrm{OLG}}^{\max }>0.9$ & 221.3 & 91.4 & 92.6 & -0.3 & -1.4 & -0.7 \\
\hline
\end{tabular}

In the column on the left, the levels of consumption tax rates that maximize output and utility of the different agents are given. In the remaining columns the changes in output, welfare, and dispersion are given, as compared to the baseline. Some values are outside the feasible range of taxes in our model and are thus marked with a ">" sign.

When comparing the results from Tables 2-4, two main differences become apparent:

(i) The dispersion in all variables is strongly reduced by capital tax financing of public spending, while labor tax financing increases it. A consumption tax hardly changes the dispersion in all variables.

(ii) A consumption tax enhances the economy's output the most for a tax rate up to $20 \%$. Above that threshold a labor tax outperforms the consumption tax, while a capital tax performs worst. We attribute this to the disincentive to accumulate capital caused by the capital tax. For higher tax levels aggregate efficiency is highest for labor taxation, since labor taxation in this setup reduces leisure time thus causing middle-income households to work more and thereby increasing the public capital stock. 
(i) and (ii) together suggest an equity-efficiency trade-off between inequalityreducing capital tax financing and efficiency-enhancing consumption tax financing.

By contrast all taxes constitute a Pareto improvement up to a certain tax rate. This result depends crucially on the base level of public capital. When the public capital stock is already at its optimal level, further investment does not enhance both agents' welfare and thus will not lead to a Pareto improvement.

The fact that the optimal tax rates (and with it the optimal levels of infrastructure provision) differ between the households has an important consequence for an optimizing government: Providing infrastructure beyond the optimum of one of the two classes always involves a trade-off between the welfare of the different classes, at least for capital and labor tax financing. For those financing instruments, further normative assumptions would be necessary to determine the optimal tax level. Those normative assumptions can be avoided if infrastructure is financed via consumption taxes: For this case the trade-off between the middle and the high-income household disappears since both agents prefer the same tax rate.

\subsection{Transitional Dynamics}

In addition to the steady-state analysis we also analyze the transitory dynamics of the system, since short-run distributional effects can go into opposite directions than long-run effects. We examine the impact of an unanticipated policy shock: When the system is in a steady state, public spending is increased from the baseline level to a level that increases output by $30 \%$.

We find two main results: (i) Short-term effects opposite to the long-run outcome are found only in the case of labor taxation: Wealth inequality is decreased in the short run, but then converges to a steady state with increased wealth inequality (see Figure A.1 in Appendix A). (ii) A consumption tax has almost no long-run effects on the distribution, but strong short-run effects. Wealth inequality is decreased while income inequality is strongly increased in the short run (see Figure 4). The dynamics for a capital tax are displayed in Figure A.2, which can be found in Appendix A.

Short-term effects for both labor and consumption can be explained as follows. The slight initial decrease in the wealth distribution can be attributed to the Pasinetti property of the system: A sudden increase in public spending increases both factor prices, thus saving of both agents increases. Since the high-income household wants to force the interest rate back to the Pasinetti level, she decreases her saving. Wealth inequality is then reduced until the interest rate converges to the Pasinetti level, determined by high-income household's time preference rate. The strong reaction of the income distribution for a labor and a consumption tax can also be explained by the Pasinetti Paradox: A sudden increase in public spending increases both factor prices. Since the interest rate before the shock is already at its Pasinetti level, the productivity-enhancing shock causes the interest rate to converge to its steady-state levels from above, while the wage rate converges to its steady-state 


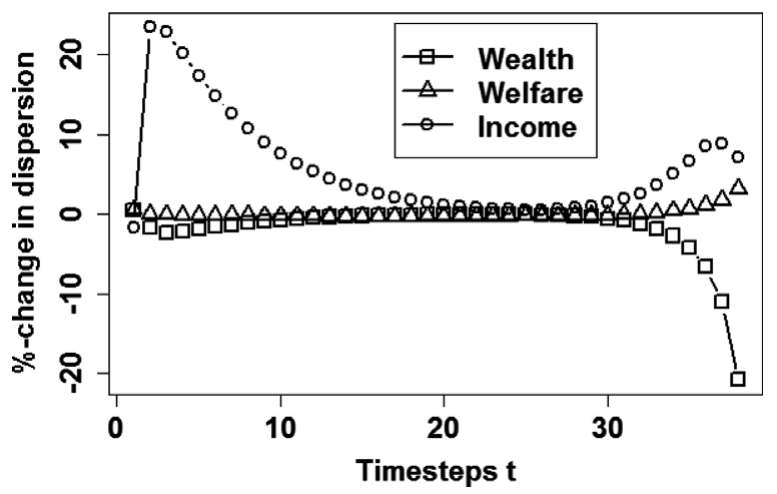

FIGURE 4. Transitory effects of an unanticipated increase of the consumption tax from the baseline steady state to a new steady state. The new steady state has a $30 \%$ higher output level than the baseline. Even though the long-run effects of consumption tax-financed public investment are almost distribution-neutral, there are strong short-run effects.

levels from below. This leads to higher capital income than wage income in the short run and thus to increased income inequality. This effect is not visible at the moment of the shock, $t=0$, since the savings level of the middle-income household has already been determined in the time step preceding the shock.

In the case of capital taxation (see Figure A.2, Appendix A) dispersion in all variables converges to its steady-state value without noteworthy short-run effects except for the strong initial decrease in the income dispersion that accrues to the fact that middle-income households determine their savings in the period before the shock.

\section{EXTENSIONS AND ROBUSTNESS}

This section consists of two main parts. In Section 4.1, we present three extensions to the model: the case of endogenous growth, lump-sum tax-financed public spending, and debt-financed public spending.

An extensive discussion of the robustness of our findings is presented in Section 4.2. We focus on both, the robustness across theories and assumptions (Section 4.2.1), as well as on the robustness across parameter values (Section 4.2.2).

\subsection{Extensions}

4.1.1. Endogenous Growth Analysis. This section summarizes our findings from the endogenous growth version of the model. It can be seen as the analogue to Section 3.1 for the case of endogenous growth. In order to obtain constant instead of diminishing returns in accumulable factors, we set $\beta=1-\alpha$ (see Section 2.1). For this parameter choice the economy converges to a steady growth 


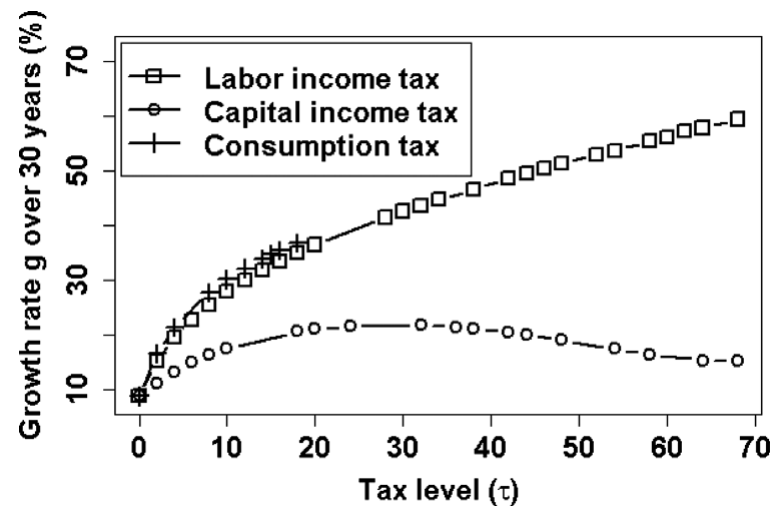

FIGURE 5. Effects of public investment on the steady-state growth rate: A consumption tax is the most growth-enhancing way to finance infrastructure investment, directly followed by a labor tax. A capital-tax is the least growth-enhancing policy instrument. Growth reaches its maximum already at a $30 \%$ capital tax, while the other taxes enhance growth up to their maximum levels.

path on which consumption and capital for both agents, as well as output, public capital and the composite externality grow at the same rate $g$.

The differences to the steady-state analysis are mainly driven by the fact that the Pasinetti Paradox does not occur in the case of endogenous growth (for more details on the Pasinetti Paradox, see Section 2.5). Along the growth path, we consider changes in the growth rate rather than in output as an indicator of efficiency.

We obtain three main results: (i) Similar to the steady-state analysis, consumption tax-financed public investment is the most efficient policy, at least up to $20 \%$, followed by a labor tax financing. Capital tax financing is the least growthenhancing policy (see Figure 5). (ii) Capital and labor taxation yield results very similar to the steady-state analysis, except for slight variations in the case of low tax rates, which are explained below (Figure 6, a and b). (iii) The results for a consumption tax deviate from the steady-state results (Figure 6c). This behavior is analyzed in detail below.

For labor tax rates up to $20 \%$, income and welfare dispersion increase as in the steady-state analysis (see Figure 6b). But wealth dispersion slightly decreases, an effect that we obtain only because public capital is very productive in the case of endogenous growth. This outcome can be explained by examining the effects of an increase in labor tax-financed infrastructure spending:

(1) Leisure $\left(l_{t}\right)$ decreases because the quality of public capital is enhanced, while total capital increases. This leads to a decreased interest rate and an increased wage rate [see equations (3) and (4)].

(2) Public capital and thus the composite externality is increased, which enhances both the interest and the wage rate. ${ }^{11}$ 

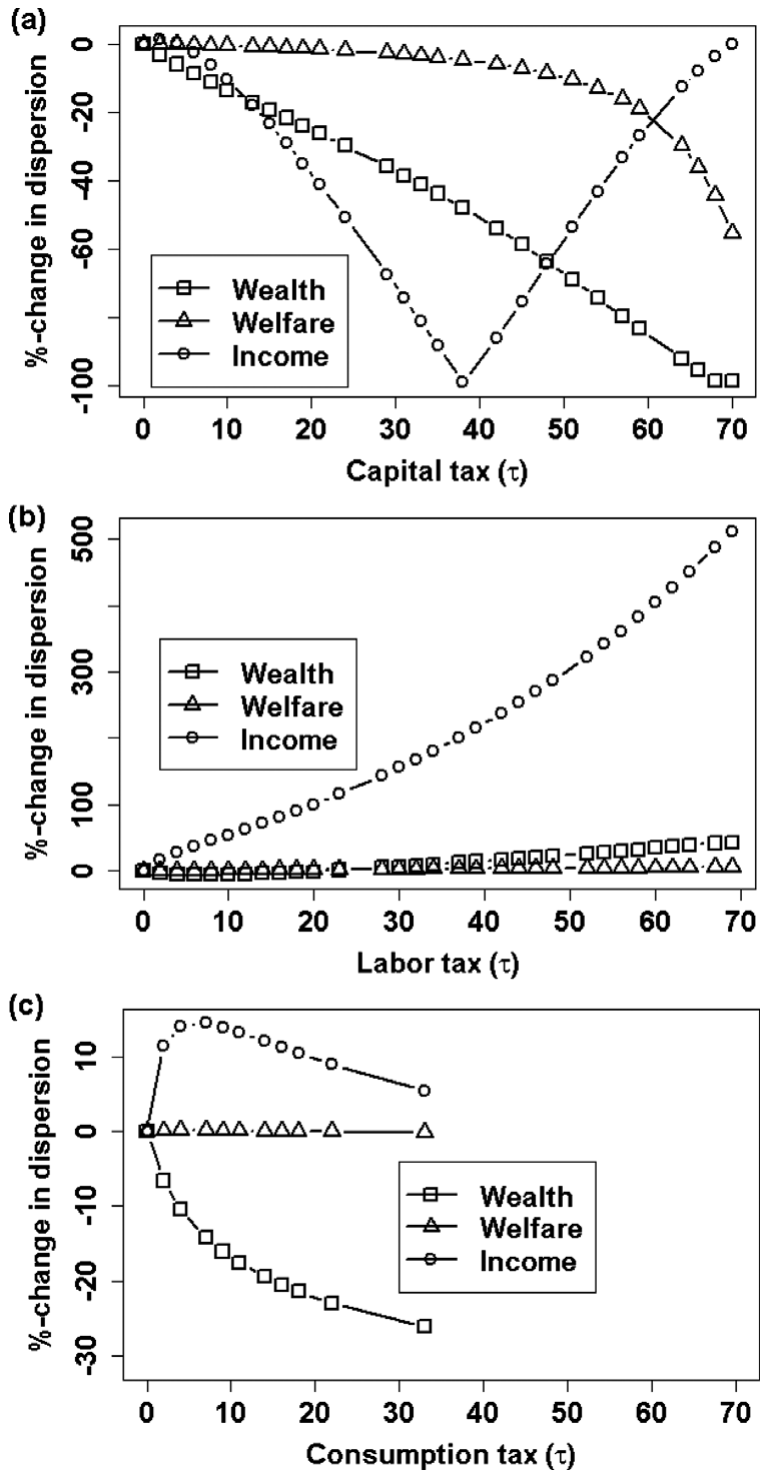

FIGURE 6. Effects of infrastructure financing through (a) capital, (b) labor, and (c) consumption taxation on the dispersion of wealth, welfare, and income for the case of endogenous growth. The downward spikes in panel (a) reflect the points where middle-income households are equal in a certain variable to high-income households. For even higher tax rates the dispersion increases again, but this time the middle-income households are better off. 
(3) Combining (1) and (2) leads to increases in both factor prices since effect (2) outweighs effect (1) for the interest rate. However, it also leads to an increased ratio of wage rate to interest rate due to effect (1).

For small tax rates the productivity-enhancing effect of public capital more than offsets the negative effect of taxation and due to (3), the middle-income households' savings are affected more strongly by labor tax-financed public spending than the high-income households' savings. ${ }^{12}$

For tax rates below $8 \%$, effect (2) is also at work in the case of a capital tax, which leads to a small increase in income dispersion (see Figure 6a). From $8 \%$ on the negative effect of capital taxation outweighs this effect. Both of these effects are quite small for our current parameterization.

Consumption tax-financed infrastructure investment leads to a decreased wealth dispersion, but to an increase in income dispersion for taxes up to $10 \%$. For higher consumption taxes the income dispersion declines as well. There is hardly any effect on welfare dispersion (Figure 6c).

The mechanisms of an increase in the consumption tax are the same as for a labor tax, so (1)-(3) still hold. But the negative effect of labor taxation on the middle-income households' income is missing, so for tax rates above $10 \%$, the middle-income households' income is affected more strongly by infrastructure spending than the high-income households' income and thus income dispersion declines from this point on. For tax values below $10 \%$ the strong productivityenhancing effect of infrastructure investment causes the capital component of the income to increase more strongly than the labor component, which leads to an increase in the income dispersion.

\subsubsection{Lump-Sum Tax Financing. A lump-sum tax provides a meaningful} benchmark, but it is not a feasible policy instrument in real-world politics. We introduce the case of lump-sum tax-financed public spending to exclude the distortive effects the other taxes have on the economy. This allows us to decouple to the distributional effect of public spending from that of its financing. ${ }^{13}$

When the model converges to a steady state, we find that lump-sum taxes distort the economy far less than the other tax mechanisms and therefore lead to the highest output levels (770\%; see Table 5).

Concerning the distributional effects in the steady state (see Figure 7, left), welfare inequality is slightly increased while wealth and income inequality decrease. Those distributional effects are a consequence of the Pasinetti property of the model: The interest rate remains at the level of the high-income household's time preference rate, even though increased public spending and increased working hours have an increasing effect on both factor prices. The only control variable for the high-income household to maintain the interest rate at its Pasinetti level is its saving, which is thus reduced compared to the middle-income household's saving, which leads to decreased wealth and income inequality. Welfare inequality remains almost unchanged, since the middle-income household's welfare increase 
TABLE 5. Steady-state effects of a lump-sum tax-financed increase in public spending

\begin{tabular}{lcccccc}
\hline & $\mathrm{dY}(\%)$ & $d u_{\mathrm{ILA}}(\%)$ & $d u_{\mathrm{OLG}}(\%)$ & $d \sigma_{K}(\%)$ & $d \sigma_{u}(\%)$ & $d \sigma_{\mathrm{Inc}}(\%)$ \\
\hline$\tau_{Y}^{\max }=0.82$ & 770 & 92.8 & 93.1 & -50.7 & -0.3 & -90.1 \\
$\tau_{u, \mathrm{ILA}}^{\max }=0.58$ & 528.7 & 95.6 & 95.0 & -36.9 & 1.2 & -81.0 \\
$\tau_{u, \mathrm{OLG}}^{\max }=0.56$ & 509.9 & 95.6 & 95.0 & -35.8 & 1.1 & -78.6 \\
\hline
\end{tabular}

In the column on the left, the levels of lump-sum tax rates that maximize output and utility of the different agents are given. The remaining columns display the changes in output, welfare, and dispersion in percent, as compared to the baseline. The lump-sum tax is given as percentage of output.
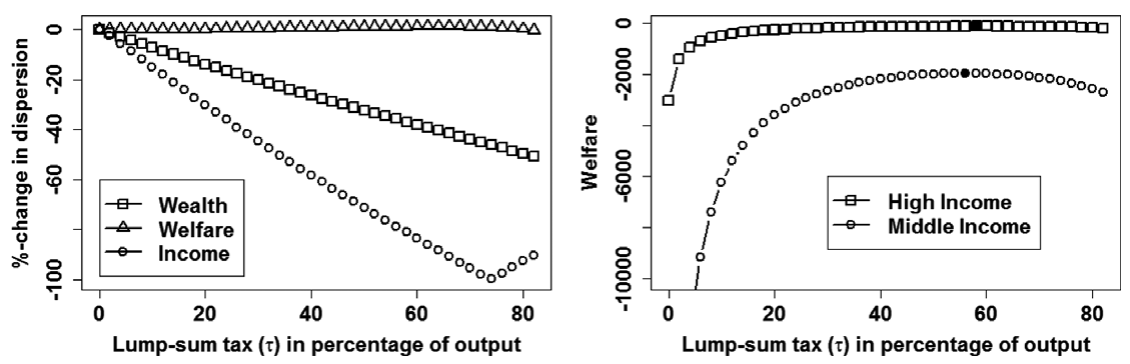

FIGURE 7. Effects of lump-sum tax-financed public investment on the dispersion of wealth, welfare, and income (left) and on the welfare of both agents (right).

that occurs through increased income, is offset by its leisure reduction. As in the case of capital and labor tax financing, there is a difference between the tax rates that maximize output and those that maximize welfare of the different households (see Table 5 and Figure 7, right).

The distributional effects in the transition to the steady state are displayed in Figure 8. While welfare inequality converges smoothly to its steady-state levels, inequality in income and wealth converge less smoothly: Through the initial productivity-enhancing effect of public capital both factor prices increase, which causes the high-income household's income to rise faster than that of the middleincome household, so income inequality is increased in the first timesteps after the shock. In the following timesteps, the interest rate converges to its steady-state rate from above, while the wage rate converges to its steady-state level from below. This causes income inequality to decrease, eventually below its initial level. Wealth inequality decreases strongly in the beginning, since the high-income household's only reaction to high interest rates is to decrease its saving relative to the saving of the middle-income household. With the interest rate returning to its Pasinetti level, the wealth distribution converges to its steady-state level from below. Figure 8 considers an increase in the lump-sum tax from 0 to $10 \%$ of output. ${ }^{14}$

4.1.3. Public Debt. Since government debt is frequently observed as a means for financing public investment in the real world, we summarize the results of 


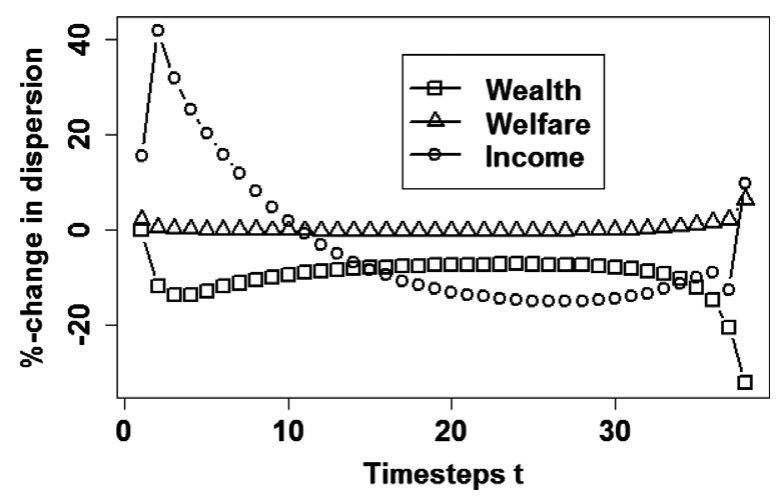

FIGURE 8. Transitory effects of an unanticipated increase of the lump-sum tax from the baseline steady state to a new steady state (in which the lump-sum tax amounts to $10 \%$ of the economy's output).

an analysis on the distributional effects of debt as a financing mechanism in this section. We conduct an experiment in which we compare the transitional dynamics of consumption tax-financed public spending with the dynamics when public spending is financed via debt, with a consumption tax used for debt servicing. The detailed analysis is available from the authors upon request.

We find that, apart from a strong progressive effect in the first period after the shock, debt financing does not smooth the distributional curves in the transition to the steady state, it even increases short-run variations. Furthermore, if debt is serviced by a consumption tax, long-run inequality is increased. This result hints at the fact that government bonds have a regressive effect, since we have shown in Section 3.1.3 that financing public spending via consumption taxes is distribution-neutral.

We limit ourselves to the reduced experiment described above, since a full-scale analysis of the equity and efficiency effects of government debt with all the model variations observed in Sections 3 and 4.1.1 would go beyond the scope of this article. $^{15}$

\subsection{Robustness}

In this subsection, we give further insights on the robustness of our results across theories and model assumptions (Section 4.2.1) and we summarize the results of an extensive sensitivity analysis (Section 4.2.2).

4.2.1. Theoretical Robustness. Our model is distinguished from previous work on the subject by assuming more sources of household heterogeneity: heterogeneous saving behavior (dynastic vs. life cycle), income sources and heterogeneous time preference rates. Although we believe that all these sources of 
TABLE 6. Selected literature on the equity and efficiency effects of public investment, with and without heterogeneity in the time preference rate $\rho$ across households in neoclassical and endogenous growth models

\begin{tabular}{lcc}
\hline & Endogenous growth & Neoclassical growth \\
\hline Identical $\rho$ & Chatterjee and Turnovsky (2012) & Glomm and Ravikumar (1994) \\
& Alesina and Rodrik (1994) & Section 4.2.2 \\
Heterogeneous $\rho$ & Angyridis (2015) & Section 3.1 \\
& Section 4.1.1 & \\
\hline
\end{tabular}

Our contributions are indicated by the section numbers of this article. Note that in our model it is technically possible to also contribute to the first quadrant of this table (endogenous growth with identical time preference rates), but this experiment is excluded for brevity.

heterogeneity are necessary to explain observed wealth disparities in industrialized countries [Cagetti and De Nardi (2008); De Nardi and Yang (2014)], one may conclude that, from a theoretical point of view, this limits the scope of our analysis.

However, the major advantage of the structure of our model, combining an infinitely lived with an overlapping generations agent, is great robustness in crucial modeling assumptions: While our main results are formulated in a neoclassical growth framework, we demonstrate in Section 4.1.1 that the results for labor and capital tax financing also hold for the case of endogenous growth. Furthermore, our analysis is conducted with heterogeneous time preference rates across agents. They seem to be the empirically realistic case [Lawrance (1991); Green et al. (1996); Dynan et al. (2004)], but have not been considered in previous work on the subject. Identical time preference rates are just a special case, leading to no particular change in behavior in our model (in Section 4.2.2, we present the results of a numerical experiment on this).

Previous work on modeling household heterogeneity in a dynamic setting that focused on initial endowments only, either chose endogenous growth models, i.e., constant returns to accumulable factors, or limited itself to the analysis of the transition to the steady state. The reason is that in the neoclassical growth model (i.e., decreasing returns to accumulable factors) with heterogeneity only in initial endowments and no further assumptions, the long-run distribution is indeterminate, in the sense that every possible distribution of capital is consistent with the steady state [Becker (2006)] ${ }^{16}$ Heterogeneous time preference rates in the neoclassical model; however, lead to a steady state in which the agent with the lowest time preference rate owns all capital in the long run, while less patient agents immediately consume all of their income and thus lead a "working poor" existence [Becker $(1980,2006)]$. We are only aware of one article that analyzes the case of heterogeneous time preference rates in an endogenous growth model, but this article has a somewhat different focus: Angyridis (2015) analyzes the equity and growth impacts of budget-neutral fiscal policy reforms when the government has access to nonlinear income taxes. This discussion is summarized in Table 6. 
TABLE 7. Sensitivity analysis of the model

\begin{tabular}{llc}
\hline Symbol & \multicolumn{1}{c}{ Parameter } & Range \\
\hline$\beta$ & Exponent of $X_{p, t}$ in production & {$[0,0.4]$} \\
$(\epsilon, \varphi)$ & Exponents in composite externality & $(0,1),(0.6,0.6),(1,0)$ \\
$l_{h}$ & Leisure high-income household & {$[0,1]$} \\
$l_{o}$ & Leisure old middle-income household & {$[0.6,1]$} \\
$\rho_{h}=\rho_{m}$ & Equal time preference rates (yearly) & $1.2 \%$ \\
$\theta$ & Share of leisure in utility function & {$[0.0,3.5]$} \\
$\sigma_{\text {Intra }}$ & Intratemporal elasticity of substitution & {$[0.6,1.2]$} \\
Standard CES utility $u_{t}=\left(\frac{1}{b}\right)\left((1-\theta) C_{t}^{a}+\theta\left(X_{u, t} l_{t}\right)^{a}\right)^{\left(\frac{b}{a}\right)}, \theta=0.5$ \\
\hline
\end{tabular}

The character of the results does not change for these parameter variations.

To summarize, our model is both narrower (in the sense that more assumption on heterogeneity are made) and broader (in the sense of more robustness across growth theories) depending on one's viewpoint, when compared to previous work. Whether one considers this an improvement depends on whether one views the further assumptions on household heterogeneity as increasing realism (while maintaining modeling flexibility) or as needlessly sacrificing parsimony. In any case, the previous discussion shows that our model does not nest previous models but provides an independent alternative to exploring the impact of household heterogeneity on the effects of public investment.

4.2.2. Robustness Across Parameters. We find that our results from Section 3.1 do not change qualitatively in all of the scenarios described in Table 7. Furthermore, the results for capital and labor tax financing are very robust and are valid even beyond the parameter ranges given in this table. A detailed sensitivity analysis on which Table 7 is based is available from the authors upon request. The three most important results can be summed up as follows:

(i) For $\beta=0$ a Pareto improvement is still possible even though the composite externality is only utility-enhancing. (ii) In the case of $\theta=0$, in which the composite externality is only production-enhancing we also have the possibility of Pareto-improving policies. This means that our results do not depend on whether the composite externality affects production or utility, as long as it affects one of them positively. (iii) The results are robust in $\epsilon$ and $\varphi$, which means that they also hold with a Romer (1986) and a Barro (1990) type of representation of the roles of public and private capital. Thus, our assumption about household heterogeneity is the main driver of all observed effects.

\section{CONCLUSION}

The present article studies the effect of public investment on equity and efficiency. We introduce a concept of household heterogeneity that is based on stylized 
facts about empirical saving behavior and differences in income sources and time preference. We make two main contributions:

First, we find that in the long run, capital tax-financed public investment can enhance the total levels of wealth, welfare, and income up to a certain tax rate and, at the same time, reduces inequality in these economic variables. Consumption tax financing also enhances productivity but leaves inequality in wealth, welfare, and income virtually unaffected in the long run. This demonstrates that for these two financing mechanisms there is a tax range in which no equity-efficiency trade-off exists for the financing of public capital. We only find such a tradeoff in case of labor tax financing since taxing labor income increases inequality but enhances the total levels of wealth, welfare, and income (up to a certain level). We also compute the optimal tax levels for all three financing possibilities and find that agents differ in their preferred level. In sum, these results show that our assumptions about household heterogeneity lead to conclusions on the equity impacts of public investment that partially confirm and partially differ from previous work on the subject: Differences concern the case of consumption tax financing (for all inequality indicators) and capital tax financing, when wealth and welfare are considered as inequality indicators.

Second, the type of model examined in this article yields very robust results with regard to the modeling assumptions. The results neither depend on the assumption of homogeneous time preference rates across households nor on the assumption of endogenous growth. ${ }^{17}$ Concerning the role of private and public capital in production, the results remain qualitatively the same if a Romer (1986), a Barro (1990) or an intermediate formulation is chosen, and they do not dependent on the dual role private and public capital play in productivity and utility, as long as it affects one of the factors positively.

We find that the equity and efficiency impacts of public investment are highly sensitive to the way heterogeneity is modeled. In the light of these findings, we agree with Diamond and Saez (2011, p. 166), who, in a recent article on the policy relevance of modeling results, argue that "we should view with suspicion results that depend critically on very strong homogeneity or rationality assumptions." We thus conclude that a proper analysis of the equity and efficiency effects of public policies should take into account differences in household characteristics that are beyond initial endowments.

The modeling presented in this article could be extended to assess additional questions of public policy, for example climate policy, health spending, or pension systems. A further refinement of the model structure could be to include mobility between income classes similar to García-Peñalosa and Turnovsky (2015), the transmission of human capital within families as in Becker and Tomes (1986), and the existence of public insurance schemes as, for instance, in Meijdam and Verbon (1997). Optimal policies could be derived by introducing an optimizing government with different welfare functions, in order to evaluate the implications of different welfare norms on equity and efficiency of the economy. 


\section{NOTES}

1. There are other factors that also influence the wealth distribution but go beyond the scope of this work: For instance the transmission of human capital within families and the existence of public insurance systems [De Nardi and Yang (2014)] as well as differences in rates of return [Guvenen (2006)].

2. A stylized way to include the low-income households in our model is to include them in the middle-income group. We explore this approach in Appendix E and demonstrate that it does not change our main results significantly.

3. In order to highlight the underlying mechanisms, we choose to look at only two extreme cases of saving behavior: completely altruistic in the case of the ILA, and pure life cycle in the case of the overlapping generations agent.

4. Since most public goods such as for example infrastructure and health care affect productivity and utility at the same time, it is crucial to account for both channels to avoid incorrect conclusions. See Chatterjee and Ghosh (2011) for more details.

5. Other studies do not consider consumption taxes or find a strong negative effect of consumption tax financing on the distribution in the long run.

6. Most theoretical articles on public investment use endogenous growth models based on Barro (1990) and Turnovsky (1997) since the relationship between growth and public investment is their main focus. Glomm and Ravikumar (1994), by contrast, use a model with steady-state convergence. However, to avoid an indeterminate steady-state wealth distribution, they assume imperfect capital markets. Our model delivers meaningful results for both approaches (without assuming imperfect capital markets).

7. In Section 4.1, we also consider financing of public capital through government bonds and lump-sum taxes.

8. Some parts of the tax incidence also fall on the middle-income households through the depressing effect a capital tax can have on the wage rate. In our model, this effect is offset by the positive effect of public investment on both factors.

9. In the case of a capital tax, the labor-leisure decision plays only a minor role: Total leisure for the middle-income households is slightly decreased since the value of leisure increases due to an increase in the composite externality. The composite externality increases as long as the increase in public capital offsets the decrease in private capital.

10. Consumption tax financing can be slightly regressive or progressive, conditional on the role leisure plays in the utility function: Depending on the leisure endowment of old middle-income households $l_{o}$ and the intratemporal elasticity of substitution $\sigma_{\text {Intra }}$, the change in dispersion varies between $[-4.7 \%, 2.3 \%]$ for the parameter ranges of these variables examined in the sensitivity analysis (see Table 7). Nevertheless these distributional effects are still more than an order of magnitude smaller when compared to the other financing mechanisms. See Section 4.2.2 for details on the sensitivity analysis.

11. An effect unobserved in the case without endogenous growth, in which the interest rate always stays at the level determined by the high-income households' time preference rate due to Pasinetti's Paradox.

12. This effect is not visible in the income dispersion since the labor component of the middle-income households' income benefits less from labor tax-financed infrastructure spending than the capital component due to the negative impact of the labor tax. The overall effect is that the middle-income households' income benefits less from infrastructure spending than the high-income households' income.

13. We implement the lump-sum tax such that each household pays the same amount in per capita terms. Since high-income households only make up 5\% of the population, middle-income households make up 55\% and low-income households are not included, high-income households end up paying $1 / 12$ of the lump-sum tax, while middle-income households pay for the remaining $11 / 12$. 
14. Looking at a tax that increases output by $30 \%$, as we did for capital, labor, and consumption taxation in Section 3.2, only leads to a lump-sum tax of $0.0162 \%$ of output. For this tax level, the distributional effects are not pronounced enough for displaying them graphically. We thus decided to rather fix the total amount of revenue to be raised and to set the lump-sum tax accordingly.

15. Further interesting experiments would include relaxing the assumption that both middle- and high-income households have access to the same type of government bonds, or the assumption that debt is serviced after one period, investigating other channels for debt servicing, or considering the case of externally held debt (to exclude the capital accumulation-reducing effect of internally held debt).

16. Chatterjee (1994) points out that in the case of imperfect capital markets, in which each household invests in its privately owned firm, the distribution in the long run would be completely equal, since capital poor agents would get higher rates of return on capital. This is also the mechanism behind the long-run outcome in Glomm and Ravikumar (1994). Chatterjee (1994) furthermore demonstrates that assuming perfect capital markets can also lead to a determinate steady-state distribution, if households are assumed to have consumption levels above a positive minimum threshold (which leads to different savings rates across households).

17. Only the results for consumption tax financing are sensitive to the assumption of endogenous growth.

\section{REFERENCES}

Alesina, A. and D. Rodrik (1994) Distributive politics and economic growth. Quarterly Journal of Economics 109(2), 465-490.

Angyridis, C. (2015) Endogenous growth with public capital and progressive taxation. Macroeconomic Dynamics 19, 1220-1239.

Attanasio, O.P. (1994) Personal saving in the United States. In J.M. Poterba (ed.), International Comparisons of Household Saving, pp. 57-124. Chicago: University of Chicago Press.

Barro, R.J. (1990) Government spending in a simple model of endogeneous growth. Journal of Political Economy 98(S5), 103-125.

Becker, G.S. and N. Tomes (1986) Human capital and the rise and fall of families. Journal of Labor Economics 4(3), 1-39.

Becker, R.A. (1980) On the long-run steady state in a simple dynamic model of equilibrium with heterogeneous households. Quarterly Journal of Economics 95(2), 375-382.

Becker, R.A. (2006) Equilibrium dynamics with many agents. In R.-A. Dana, C. Le Van, T. Mitra and K. Nishimura (eds.), Handbook on Optimal Growth 1. Discrete Time, pp. 385-442. Berlin: Springer.

Browning, M. and A. Lusardi (1996) Household saving: Micro theories and micro facts. Journal of Economic Literature 34(4), 1797-1855.

Cagetti, M. and M. De Nardi (2008) Wealth inequality: Data and models. Macroeconomic Dynamics 12(S2), 285-313.

Calderón, C. and L. Servén (2014a) Infrastructure and inequality. In S.N. Durlauf and L.E. Blume (eds.), New Palgrave Dictionary of Economics, Online Edition. Basingstoke, UK: Palgrave Macmillan. Accessed 1 December 2014.

Calderón, C. and L. Servén (2014b) Infrastructure and growth. In S.N. Durlauf and L.E. Blume (eds.), New Palgrave Dictionary of Economics, Online Edition. Basingstoke, UK: Palgrave Macmillan. Accessed 1 December 2014.

Carroll, C.D. (2000a) Requiem for the representative consumer? Aggregate implications of microeconomic consumption behavior. American Economic Review 90(2), 110-115.

Carroll, C.D. (2000b) Why do the rich save so much? In Joel B. Slemrod (ed.), Does Atlas Shrug? Economic Consequences of Taxing the Rich, pp. 465-484. Cambridge, MA: Harvard University Press. 
Chatterjee, S. (1994) Transitional dynamics and the distribution of wealth in a neoclassical growth model. Journal of Public Economics 54, 97-119.

Chatterjee, S. and S. Ghosh (2011) The dual nature of public goods and congestion: The role of fiscal policy revisited. Canadian Journal of Economics/Revue canadienne d'Economique 44(4), 1471-1496.

Chatterjee, S. and S.J. Turnovsky (2012) Infrastructure and inequality. European Economic Review $56,1730-1745$.

De Nardi, M. and F. Yang (2014) Bequests and heterogeneity in retirement wealth. European Economic Review 72, 182-196.

Diamond, P. and E. Saez (2011) The case for a progressive tax: From basic research to policy. Journal of Economic Perspectives 25(4), 165-190.

Diaz-Gimenez, J., A. Glover, and J.-V. Rios-Rull (2011) Facts on the distributions of earnings, income, and wealth in the United States: 2007 Update. Federal Reserve Bank of Minneapolis Quarterly Review 34(1).

Dynan, K.E., J. Skinner, S.P. Zeldes, S. Journal, N. April, and K.E. Dynan (2004) Do the rich save more? Journal of Political Economy 112(2), 397-444.

Gale, W.G. and J.K. Scholz (1994) Intergenerational transfers and the accumulation of wealth. Journal of Economic Perspectives 8(4), 145-160.

García-Peñalosa, C. and S.J. Turnovsky (2015) Income inequality, mobility, and the accumulation of capital. Macroeconomic Dynamics 19, 1332-1357.

Glomm, G. and B. Ravikumar (1994) Growth-inequality trade-offs in a model with Public Sector R\& D. Canadian Journal of Economics/Revue canadienne d'Economique 27(2), 484-493.

Green, L., J. Myerson, D. Lichtman, S. Rosen, and A. Fry (1996) Temporal discounting in choice between delayed rewards: The role of age and income. Psychology and Aging 1, 79-84.

Guvenen, F. (2006) Reconciling conflicting evidence on the elasticity of intertemporal substitution: A macroeconomic perspective. Journal of Monetary Economics 53(7), 1451-1472.

Krusell, P. and A.A. Smith (1998) Income and wealth heterogeneity in the macroeconomy. Journal of Political Economy 106(5), 867-896.

Lawrance, E.C. (1991) Poverty and the rate of time preference : Evidence from panel data. Journal of Political Economy 99(1), 54-77.

Mattauch, L., O. Edenhofer, D. Klenert, and S. Bénard (2016) Distributional effects of public investment when wealth and classes are back. Metroeconomica 67(3), 603-629.

Meijdam, L. and H. a. a. Verbon (1997) Aging and public pensions in an overlapping generations model. Oxford Economic Papers 49, 29-42.

Michl, T.R. (2009) Capitalists, Workers, and Fiscal Policy. Cambridge, MA: Harvard University Press.

Pasinetti, L.L. (1962) Rate of profit and income distribution in relation to the rate of economic growth. Review of Economic Studies 29(4), 267-279.

Quadrini, V. (1997) Understanding the U. S. distribution of wealth. Federal Reserve Bank of Minneapolis Quarterly Review 21(2), 22-36.

Ray, D. (1997) Development Economics. Princeton, NJ: Princeton University Press.

Romer, P.M. (1986) Increasing returns and long-run growth. Journal of Political Economy 94(5), $1002-1037$.

Stiglitz, J.E. (1969) Distribution of income and wealth among individuals. Econometrica 37(3), 382397.

Stiglitz, J.E. (2015) New Theoretical Perspectives on the Distribution of Income and Wealth among Individuals Part II: Equilibrium Wealth Distributions. NBER Working Paper Series 21190.

Turnovsky, S.J. (1997) Fiscal policy in a growing economy with public capital. Macroeconomic Dynamics 1, 615-639.

Wolff, E.N. (1998) Recent trends in the size distribution of household wealth. Journal of Economic Perspectives 12(3), 131-150.

Wolff, E.N. (2010) Recent Trends in Household Wealth in the United States: Rising Debt and the Middle-Class Squeeze an Update to 2007. The Levy Economics Institute Working Paper Collection. 


\section{APPENDIX A: TRANSITIONAL DYNAMICS FOR A LABOR AND A CAPITAL TAX}

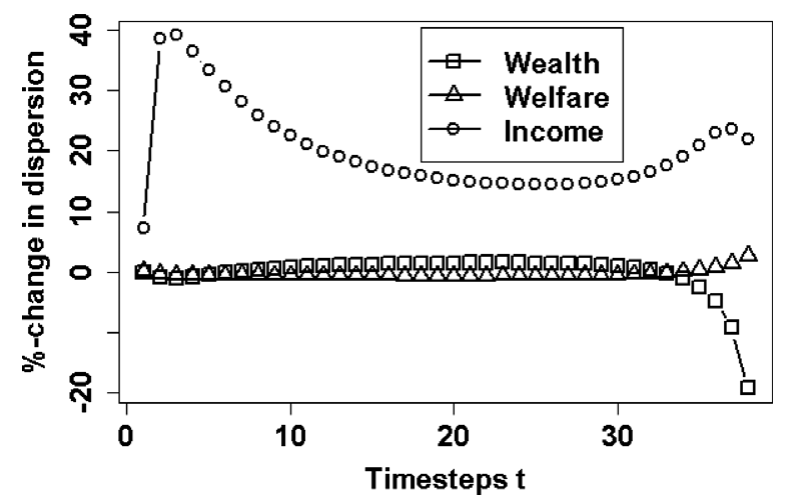

FIGURE A.1. Transitory effects of an unanticipated increase of the labor tax from the baseline steady state to a new steady state. The new steady state has a $30 \%$ higher output level than the baseline. Even though the long-term effect of labor tax-financed public investment is inequality-increasing, it decreases short-term wealth inequality.

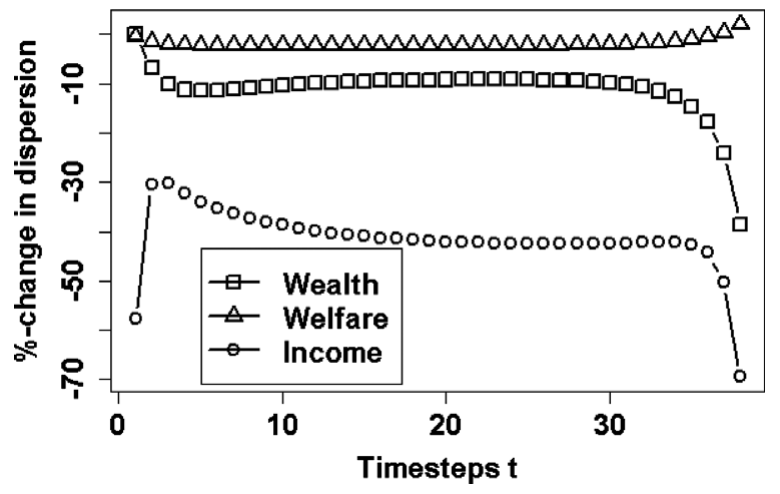

FIGURE A.2. Transitory effects of an unanticipated increase of the capital tax from the baseline steady state to a new steady state. The new steady state has a $30 \%$ higher output level than the baseline. For the case of capital tax financing, the model approximates the steady-state monotonically, except for a strong first period decrease in income inequality, which can be attributed to the fact that middle-income households choose their saving level in the period before the shock, while the high-income households choose their level of saving already anticipating the shock. 


\section{APPENDIX B: FIRST-ORDER CONDITIONS OF THE HIGH-INCOME HOUSEHOLDS}

The Lagrangian of the optimization problem of the high-income household can be written as

$$
\mathcal{L}=\sum_{t=0}^{t_{\text {final }}} u_{t}^{\mathrm{ILA}} \cdot \frac{1}{\left(1+\rho_{h}\right)^{t}}+\lambda_{t}\left\{\left[1+\left(1-\tau_{K}\right) r_{t}\right] K_{h, t}+\left(1+\tau_{c}\right) C_{t}-K_{h, t+1}\right\}
$$

The first-order conditions of the high-income household then are

$$
\begin{gathered}
{\left[1+\left(1-\tau_{K}\right) r_{t}\right] \lambda_{t}=\lambda_{t-1},} \\
\frac{\partial u_{t}^{\mathrm{ILA}}}{\partial C_{t}} \cdot \frac{1}{\left(1+\rho_{h}\right)^{t}}=\lambda_{t}\left(1+\tau_{c}\right) .
\end{gathered}
$$

Calculating the derivations in equation (7) yields the explicit Euler equation

$$
\frac{\left[C_{t-1}^{a}+\theta\left(X_{u, t-1} l_{h}\right)^{a}\right]^{(b / a-1)}}{\left[C_{t}^{a}+\theta\left(X_{u, t} l_{h}\right)^{a}\right]^{(b / a-1)}}\left(\frac{C_{t}}{C_{t-1}}\right)^{(1-a)}=\frac{1+\left(1-\tau_{K}\right) r_{t}}{1+\rho_{h}} .
$$

\section{APPENDIX C: FIRST-ORDER CONDITIONS OF THE MIDDLE-INCOME HOUSEHOLDS}

The Lagrangian of the optimization problem of the middle-income household can be written as

$$
\mathcal{L}=u_{t}^{\mathrm{OLG}}-\kappa_{t} \cdot\left\{C_{y, t}\left(1+\tau_{c}\right)+\frac{\left(1+\tau_{c}\right) C_{o, t+1}}{\left[1+\left(1-\tau_{K}\right) r_{t+1}\right]}-\left(1-\tau_{w}\right) w_{t}\left(1-l_{t}\right)\right\} .
$$

The first-order conditions are calculated as

$$
\begin{gathered}
\kappa_{t}=\frac{\partial u_{t}^{\mathrm{OLG}}}{\partial C_{y, t}} \frac{1}{\left(1+\tau_{c}\right)}, \\
\kappa_{t}=\frac{\partial u_{t}^{\mathrm{OLG}}}{\partial C_{o, t+1}} \frac{\left[1+\left(1-\tau_{K}\right) r_{t+1}\right]}{\left(1+\tau_{c}\right)}, \\
\left(1-\tau_{w}\right) w \kappa_{t}=\frac{\partial u_{t}^{\mathrm{OLG}}}{\partial l_{y, t}} .
\end{gathered}
$$

Combining equations (C.1) and (C.2), we get the Euler equation (11). By combining (C.1) and (C.3) we get equation (12). By calculating the partial derivatives of $u_{t}^{\mathrm{OLG}}$ and inserting them into equation (11) and equation (12) we get the explicit expressions

$$
\frac{C_{o, t+1}}{C_{y, t}}=\left\{\left[\frac{1+\left(1-\tau_{k}\right) r_{t+1}}{\left(1+\rho_{m}\right)}\right] \cdot\left[\frac{C_{o, t+1}^{a}+\theta\left(X_{u, t+1} l_{o}\right)^{a}}{C_{y, t}^{a}+\theta\left(X_{u, t} l_{y, t}\right)^{a}}\right]^{((b / a)-1)}\right\}^{\frac{1}{(1-a)}} .
$$


Here, we can see that only the intertemporal decision given by equation (C.4) is directly influenced by capital taxation, as this expression depends on $\tau_{k}$.

$$
\frac{l_{y, t}}{C_{y, t}}=X_{u, t}^{\frac{a}{(1-a)}}\left(\theta \cdot \frac{\left(1+\tau_{c}\right)}{\left(1-\tau_{w}\right) w_{t}}\right)^{\frac{1}{(1-a)}},
$$

By contrast, we infer from the second Euler equation (C.5) that the intragenerational laborleisure decision is only directly influenced by consumption and labor taxation: the higher the labor or consumption tax, the higher the chosen levels of leisure.

\section{APPENDIX D: STEADY-STATE EQUATIONS OF THE ECONOMY}

By formulating the equations for the system's steady state, we can gain important insights about the main drivers of steady-state behavior. Additionally, we can verify if the dynamic model, which is solved numerically, is solved correctly.

In the following, all steady-state variables are denoted by a tilde. From equations (6) and (14) it is easy to obtain an expression for the ILA's steady-state consumption $\tilde{C}$ :

$$
\tilde{C}=\rho_{h} \tilde{K}_{h}
$$

The middle-income household's first-order conditions [equations (9), (10), (C.4), and (C.5)] and the first-order conditions of the firm [equations (3) and (4)] remain the same in the steady state.

The steady-state level of public capital $\tilde{K}_{G}$ is given by

$$
\delta_{G} \tilde{K}_{G}=\tau_{K} \cdot \tilde{r} \tilde{K}+\tau_{w} \cdot \tilde{h} \tilde{w}+\tau_{c} \cdot\left(\tilde{C}+\tilde{C}_{y}+\tilde{C}_{o}\right) .
$$

Together with the equation (2) we have a system of partially nonlinear equations.

By combining the steady-state equations (14), (D.1), (D.2) with the first-order conditions of the OLG agent [(9), (10), (C.4), and (C.5)] and the firm [(3) and (4)], we can eliminate $\tilde{r}, \tilde{w}$ and $\tilde{C}$ :

$$
\begin{gathered}
\left(1+\tau_{c}\right) \tilde{C}_{y}=\left(1-\tau_{w}\right)\left((1-\alpha) A \tilde{K}^{\alpha}\right) \tilde{X}_{p}^{\beta}\left(1-\tilde{l}_{y}\right)^{(1-\alpha)}-\tilde{S}, \\
\tilde{C}_{o}=\frac{\left(1+\rho_{h}\right)}{\left(1+\tau_{c}\right)} \tilde{S}, \\
\frac{\tilde{C}_{o}}{\tilde{C}_{y}}=\left\{\left(\frac{1+\rho_{h}}{1+\rho_{m}}\right) \cdot\left[\frac{\tilde{C}_{o}^{a}+\theta\left(\tilde{X}_{u} l_{o}\right)^{a}}{\tilde{C}_{y}^{a}+\theta\left(\tilde{X}_{u} \tilde{l}_{y}\right)^{a}}\right]^{((b / a)-1)}\right\}^{\frac{1}{(1-a)}}, \\
\frac{\tilde{l}_{y}}{\tilde{C}_{y}}=\tilde{X}_{u}^{\frac{2 a-1}{(1-a)}}\left(\theta \cdot \frac{\left(1+\tau_{c}\right)}{\left(1-\tau_{w}\right)\left\{(1-\alpha) A\left[\frac{\tilde{K}}{\left(1-\tilde{l}_{y}\right)}\right]^{\alpha}\right\}}\right)^{\frac{1}{(1-a)}},
\end{gathered}
$$




$$
\frac{\rho_{h}}{\left(1-\tau_{K}\right)}+\delta_{K}=\alpha A\left[\frac{\left(1-\tilde{l}_{y}\right)}{\tilde{K}}\right]^{1-\alpha} \tilde{X}_{p}^{\beta},
$$

and

$\delta_{G} \tilde{K}_{G}=\frac{\tau_{K}}{1-\tau_{K}} \cdot \rho_{h} \tilde{K}+\tau_{w} \cdot\left(1-\tilde{l}_{y}\right)(1-\alpha) A\left[\frac{\tilde{K}}{\left(1-\tilde{l}_{y}\right)}\right]^{\alpha} \tilde{X}_{p}^{\beta}+\tau_{c} \cdot\left(\rho_{h} \tilde{K}_{h}+\tilde{C}_{y}+\tilde{C}_{o}\right)$.

For the sake of readability we did not insert the expressions for $\tilde{K}=\tilde{K}_{h}+\tilde{S}$, for $\tilde{X}_{p}=\tilde{K}^{\epsilon} \tilde{K}_{G}^{1-\epsilon}$ and for $\tilde{X}_{u}=\tilde{K}^{\varphi} \tilde{K}_{G}^{1-\varphi}$. Now, we only have a set of six partially nonlinear equations in $\tilde{K}_{h}, \tilde{S}, \tilde{K}_{G}, \tilde{C}_{y}, \tilde{C}_{o}$, and $\tilde{l}_{y}$.

\section{APPENDIX E: INCLUDING THE LOW-INCOME HOUSEHOLDS}

If low-income households are included in the model calibration, $38 \%$ of total net wealth is jointly owned by low- and middle-income households while $62 \%$ is owned by high-income households. This leads to a slight shift in the graphs on the distributional effects of public investment as displayed in Figure E.1 (black lines depict the original calibration, red lines the calibration in which low- and middle-income households jointly own $38 \%$ of the capital stock): For consumption tax financing hardly anything changes. However, the inequalityreducing effect of capital tax-financed public investment is weakened a little bit and the inequality enhancing effect of labor tax financing is increased.

We observe these effects since including the low into the middle-income class means lower per capita wealth, welfare and income levels and thus an increased dispersion of these variables. 

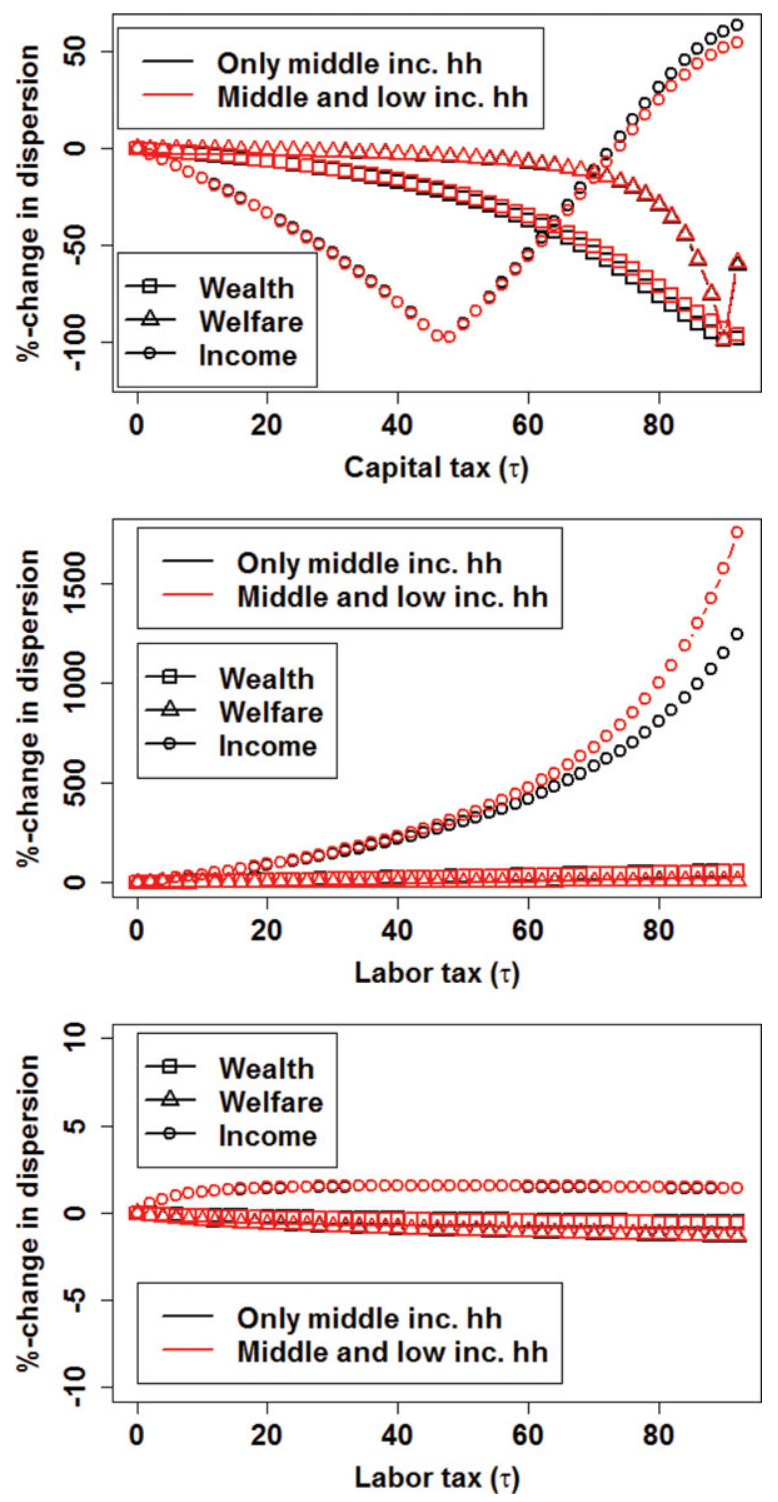

FIGURE E.1. The distributional effects of public investment for capital tax (top), labor tax (middle), and consumption tax financing (bottom). The black lines are the results with the standard calibration, in which high-income households (the top 5\%) own 62\% of total wealth and middle-income households (the next 55\%) own the remaining 38\%. The case in which low- and middle-income households jointly own $38 \%$ of total wealth is displayed with red lines. 